\title{
Nonlinear Dynamics Response of a Planar Mechanism with Two Driving Links and Prismatic Pair Clearance
}

\author{
Lijuan Wu, ${ }^{1,2}$ Dan B. Marghitu, ${ }^{1}$ and Jing Zhao ${ }^{1}$ \\ ${ }^{1}$ Department of Mechanical Engineering, Auburn University, 1418 Wiggins Hall, Auburn, AL 36849-5341, USA \\ ${ }^{2}$ Department of Mechanical Engineering, Shanghai Dianji University, Shanghai, China \\ Correspondence should be addressed to Dan B. Marghitu; marghitu@auburn.edu
}

Received 16 April 2017; Revised 16 June 2017; Accepted 20 June 2017; Published 8 August 2017

Academic Editor: Mohammed Nouari

Copyright (c) 2017 Lijuan Wu et al. This is an open access article distributed under the Creative Commons Attribution License, which permits unrestricted use, distribution, and reproduction in any medium, provided the original work is properly cited.

\begin{abstract}
The influence of the joint clearance on the dynamic response of a planar mechanism with two driving links and prismatic pair clearance is investigated under variable input speeds of the system. The simulation model was built with a nonlinear impact model. The normal contact force is characterized by Hertz contact theory and an energy dissipation term. A tangential friction force is involved in the simulation model based on Coulomb's friction law. The simulation results indicate that the largest Lyapunov exponents are dependent on the clearance size and the input speed.
\end{abstract}

\section{Introduction}

Clearance joints are found in all real mechanical systems, instead of ideal joints, which ignore the existence of tolerance and wear on joint elements. However, it has been concluded that the stability and precision of system motion are considerably degraded as a result of the impact between the elements of the clearance joint. Moreover, under certain conditions, this imperfect system tends to exhibit chaotic nonlinear behavior rather than periodicity. The complexity and importance of the clearance joints have attracted investigation for centuries. Dubowsky and Freudenstein [1] analyzed the dynamic responses of clearance joint based on an elastic model and pointed out that the characteristic is unstable, vibrant, and nonlinear. Erkaya and Uzmay [2] measured out the obvious higher vibration and noise of motion on a mechanism with clearance than that without clearance at an experimental test rig. Flores et al. [3] performed the experiment and the theory to obtain coincident results that the maximum impact acceleration increases significantly when the mechanism with clearance operates at high speed, and the important effect of clearance on dynamic performance must be considered. Houfek et al. [4-6] studied the nonlinear performance of mechanisms with clearance under various conditions and parameters; chaotic phenomenon was presented in their works.
A number of valuable works have focused on the methodology for modeling and simulation of mechanical systems with clearance joints, as well as prediction and quantification of the dynamic response based on the system parameters of clearance size, system inputs, material, and surface properties. Crank-slider and four-bar mechanisms with clearance are the typical mechanisms of these studies [7-10]. The different methods for building a dynamic model to introduce clearance into general mechanism equations from the previous studies have both its advantages and disadvantages, which will be discussed later. Furthermore, the simulation results show that the nonlinear response related to the parameters of the system. Thus, the work of modeling the dynamic model correctly and figuring out the relationships between the response and parameters of a system with clearance is very critical and still in progress. In addition, most of dynamic response studies were focused on the mechanisms which has constant system inputs and single driving link. However, in practical applications, more complex basic mechanism is of a greater value than a simple one.

In general, there exist three modes of the relative motion of clearance joint elements: the contact mode, the free flight mode, and the impact mode, which are all considered by most clearance models. According to different assumptions on the impact process (continuous or instantaneous), there are two main approaches to formulating the dynamic equations of 
motion of mechanism with clearance, namely, continuous and discontinuous; we will discuss them separately.

The first approach regards the impact as a short but continuous process accompanied by material deformation on the contact point. A linear or nonlinear continuous contact force is usually used to describe this process. For building the dynamic model of a system with clearance in free fly mode, a group basic kinematic and dynamic equation of motion is implemented, just as in an ideal system. When impactcontact occurs, a contact force is added simultaneously in the basic equations of motion as an internal form. The numerical integration algorithm continues in the whole solution process of equations. In this approach, the contact force plays a crucial role in reflecting the impact behavior as precisely as possible. Thus, the main focus is to build a force model which takes into account the material, velocity, and deformation of collision bodies. This approach was studied by many researchers [11, 12].

Timoshenko and Gere suggested a linear force model which considered the linear elastic deformation on the contact surface and energy consumption in the collision process [13].

Hertz built a nonlinear force model, but neglected the energy dissipation [14]. Hunt and Crossley introduced a damping term to represent the energy loss based on Hertz's contact law [15].

Lankarani and Nikravesh (L-N) further expressed the hysteresis damping as the function of the coefficient of restitution and the velocity before the impact [16]. The L-N force model considered both nonlinear deformation and energy loss due to impact and was widely used in later research.

Ravn used the continuous approach and the L-N force model to describe a mechanism with a rotational joint clearance. Performing this simulation has shown that all the kinematic and dynamic characteristics of the mechanism at different motion modes could be displayed as a continuous form. The chaotic behavior of the deep impact mechanics also could be analyzed further. Experimental data was presented later to verify the continuous analysis method [17].

Flores and Ambrósio compared several continuous force models from elastic deformation and energy dissipation aspects. The motion trajectories of the clearance joint elements and the relationship between the force and deformation indicated the L-N model led to a much smoother dynamic response of the system than other models [18].

However, Schwab et al. pointed out the hysteresis damping in the L-N force model is effective only for high coefficients of restitution [19]. Over the last years a good number of works [20-23] have performed studies to modify the hysteresis damping for both large and small coefficients of restitution. Modeling a contact force is still the most important work for this approach.

The second discontinuous approach assumes the impact occurs instantaneously and the system configuration does not significantly change during the short time contact. When the impact is detected, the system equation integration pauses. Meanwhile, the approach uses the momentum balance and the coefficient of restitution to calculate the velocity immediately after the impact as the initial condition when the integration is restarted. This approach was first proposed by Kane [24], Marghitu and Hurmuzlu [25], and Schwab et al. [19], who used this approach for modeling the impact mode equations for a basic mechanical system. This approach closely imitates the actual motion of clearance joint elements, but the information about the variation of contact forces and accelerations during impact is not yet available in open literature.

From the aspect of dynamic response, the influence resulted from the crucial factors of clearance size, input speed, rigidity and flexibility of bodies, lubrication, and friction in joint, which have been investigated previously to accurately predict the dynamic response of the mechanical system with clearance [26-28]. Periodic and chaotic performances were analyzed with factors on the typical mechanism of crankslider and four-bar mechanisms. Nonlinear methods such as phase space [7], center trajectory [29], Poincaré map [30], Lyapunov exponent [26], and bifurcation diagram [31] are used to study linear and nonlinear behavior.

Seneviratne and Earles [32] studied the periodic and chaotic performance of a four-bar mechanism through changing the crank speed and the realistic damping of link. The result shows that the transformation from regular to chaotic motion depends on a critical value of the input speed, slightly over the value, the clearance response characterized by nonperiodicity, and sensitive to initial conditions. They deduced that the regular and chaotic motion correspond to contact maintained and contact lost (impact occurs), respectively. The damping did not affect the response significantly.

Farahanchi and Shaw [33] studied the influence of clearance size, joint friction, crank speed, and impact parameters on the response of a crank-slider mechanism with slide clearance. The chaotic motion is prevalent for the high speeds of the crank and low joint friction. The periodic motion is observed for low values of the crank speed and coefficient of restitution. For a given set of parameter values, initial condition and time scale affected the appearance of the response. They also pointed out that slight changes in the parameters render the periodic motion to chaotic.

Flores [34] selected the parameters of the clearance size, input crank speed, and number of clearance joints as the factors to find the influence on the dynamic response of a crank-slider mechanism. Poincaré maps and journal center trajectories show that the magnifications of forces and moments are affected by the revolute clearance joints and depend on the clearance size and input crank speed. The nonlinear response is also sensitive to these parameters.

Azimi Olyaei and Ghazavi [35] used Poincaré section and fractal dimension of strange attractor of the system response to analyze the influence of constant velocity and certain clearance in a crank-slider mechanism. It was shown that the system response substantially changes when the joint clearance was introduced. System exhibits chaotic behavior under specific conditions.

Muvengei et al. [36] studied the effects of clearance size and input crank speed on the dynamic response of a typical plane crank-slider mechanism with two revolute clearance joints. From the phase portraits of the slider velocity and acceleration, it could be concluded that the chaotic or 

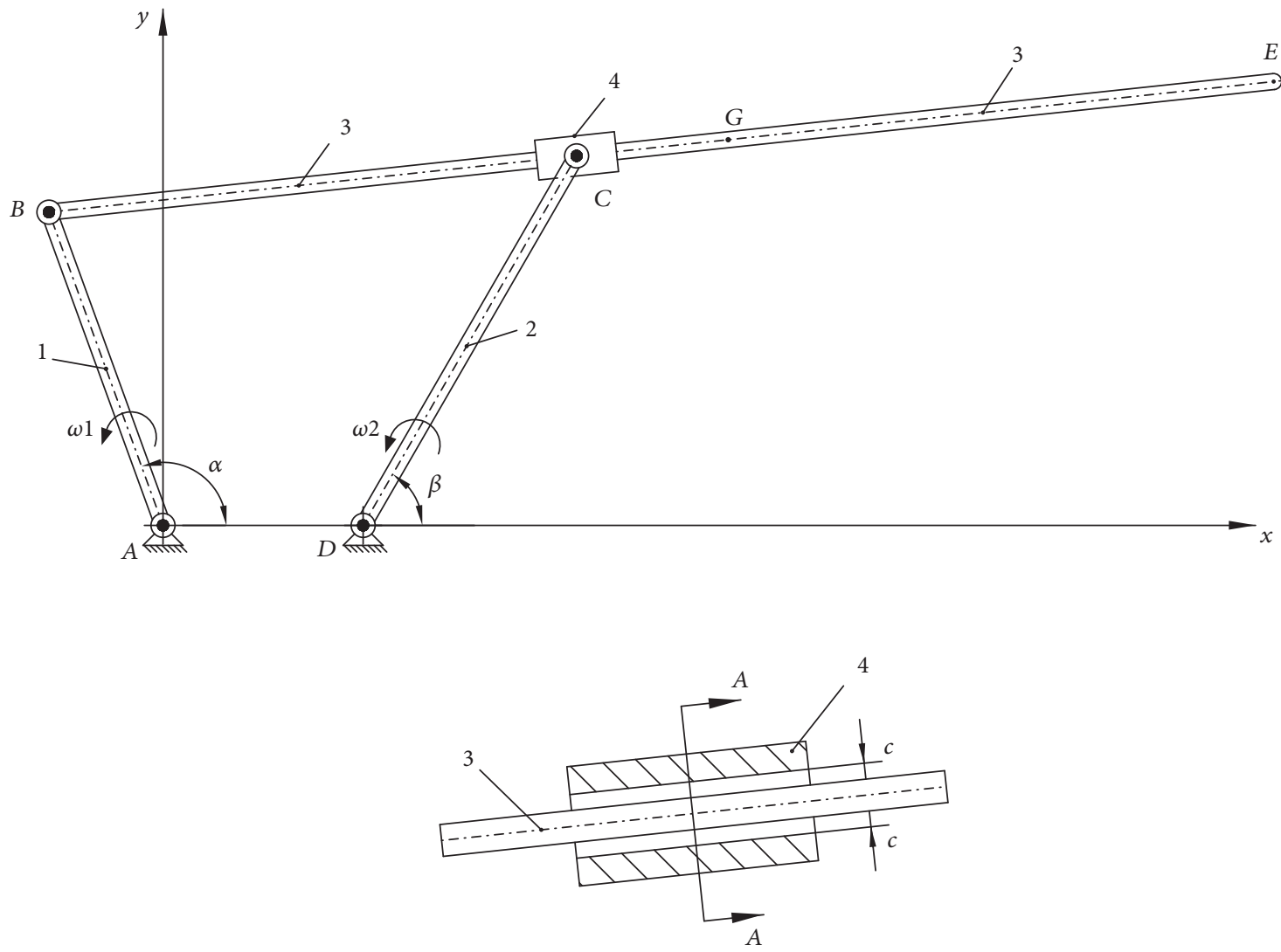

FIGURE 1: Mechanism with two driving links and clearance for the prismatic pair.

periodic dynamic response not only depends on the clearance size and the operating speed, but also relates to the location of clearance joints. Therefore, multiple clearance revolute joints should be considered when analyzing the dynamic behavior of a mechanism system.

Tang et al. [37] studied the response that resulted from the constant crank speed and the different clearance size. It was proved from Poincaré map that the phenomena of chaotic, periodic, and subharmonic response could be found in the special conditions. And a slight variance in clearance led to a quite different appearance in Poincaré map. With clearance varying gradually, the periodic response, subharmonic response, and bifurcation phenomena can be observed clearly.

In the present work, we will study the nonlinear dynamic responses of a rigid planar mechanism with two driving links and prismatic pair clearance. A series of clearance sizes and a group of input speeds, constant and variable, are individually set as the different operating conditions. The adopted contact and friction force model are presented first. Then the stability and accuracy of the mechanism motion are quantified by comparing the dynamic responses deduced from different conditions. Finally, the methods of phase plane, Poincaré section, and Lyapunov exponents are applied to analyze the effect of those parameters on periodic and chaotic behaviors. Numerical simulation has been done in ADAMS using a specific input force.

\section{Modeling of the Mechanism}

In this section, a planar model of mechanism with clearance is built as an example to investigate the influence of clearance and input speed on the dynamic behavior. Contact condition, position, and force are deduced and illustrated based on the clearance joint model presented. Figure 1 shows the planar mechanism, which consists of five rigid bodies, four ideal revolute pairs, and a prismatic pair with clearance, belonging to the double cranks slider mechanism widely used in the machinery such as slotting machine and compressor. The degrees of freedom of the mechanism become four from two when the clearance is set. The coordinate origin is set at point $A$, the gravitational acceleration is taken as acting in the negative $Y$ direction, and the mechanism motion is defined in a $X Y$ plane. The initial angles are $\alpha=110 \mathrm{deg}$ and $\beta=60 \mathrm{deg}$. Two rotation speeds are considered inputs on link 1 and link 2 , respectively, to drive the mechanism. At the prismatic pair, a clearance $c$ is introduced by the difference of slider bore and link 3 in the diameter direction. The characteristics of the bodies are given in Table 1.

2.1. Modeling of the Clearance. In a clearance prismatic pair, there are four possible states of the relative motion which are illustrated in Figure 2: (a) no contact; (b) impact-contact on a single point on the end face of slider; (c) impact-contact on two points on the opposing sides; (d) impact-contact on 
TABLE 1: Basic characteristics of bodies.

\begin{tabular}{lccc}
\hline Bodies & Length $(\mathrm{mm})$ & Mass $(\mathrm{kg})$ & Moment of inertia $\left(\mathrm{kg} \cdot \mathrm{m}^{2}\right)$ \\
\hline Link 1 & 250 & 0.392 & 0.00817 \\
Link 2 & 320 & 0.502 & 0.01713 \\
Link 3 & 900 & 1.412 & 0.07703 \\
Slider 4 & 60 & 0.211 & 0.00003 \\
\hline
\end{tabular}

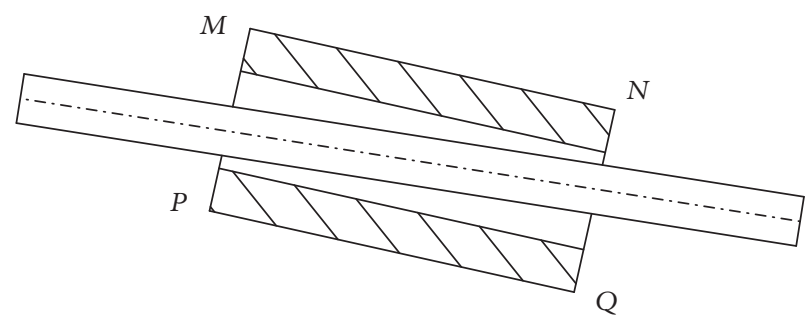

(a)

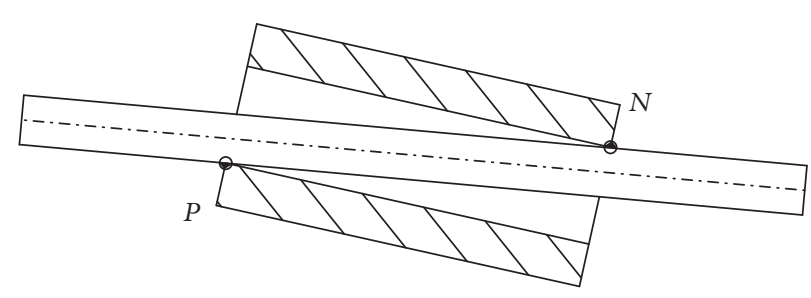

(c)

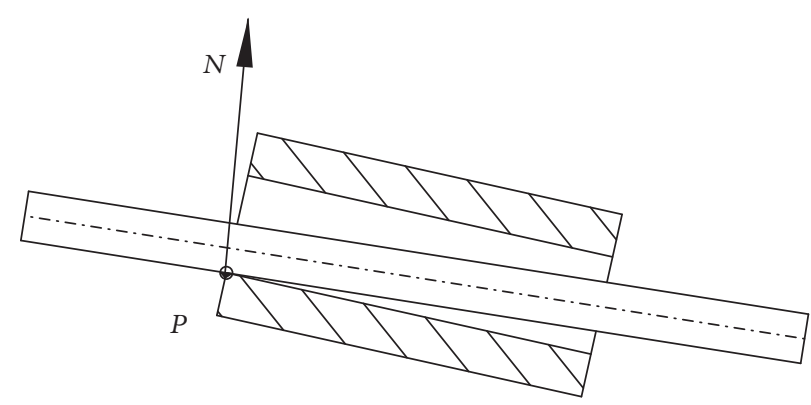

(b)

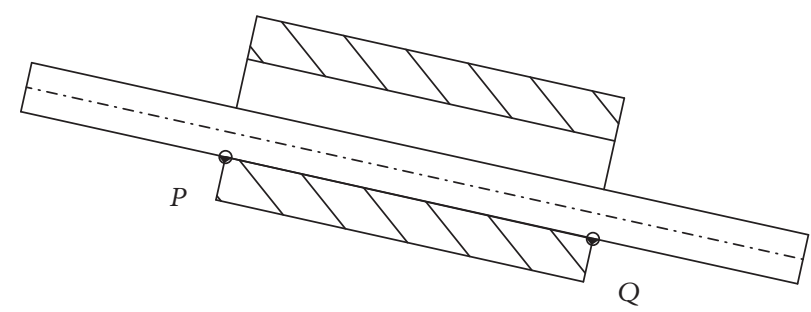

(d)

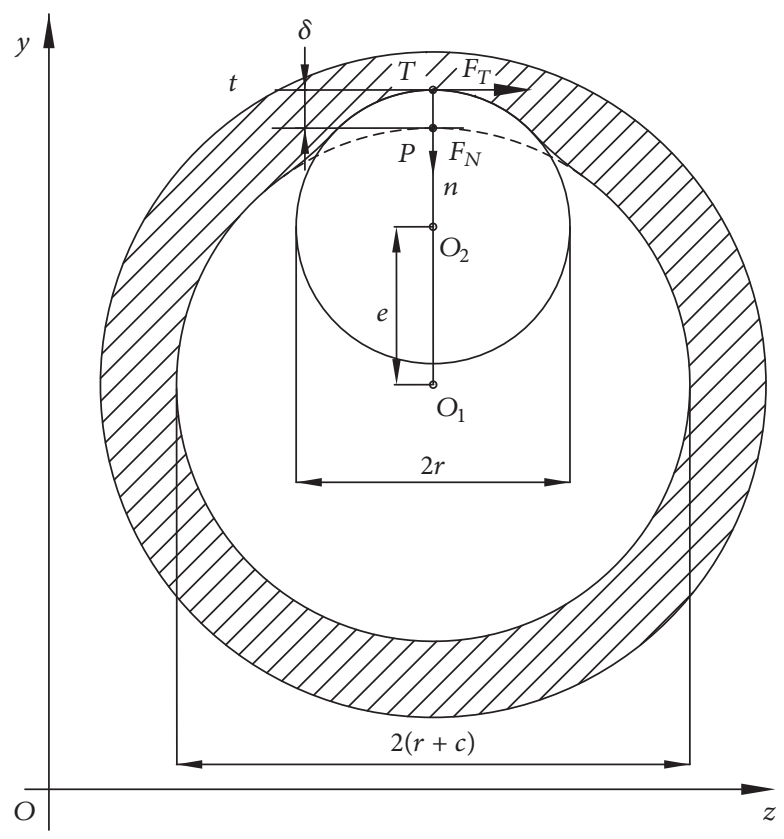

(e)

FIGURE 2: Four possible states of the relative motion.

two points on the same side. To display the contact in states clearly, the impact-contact point is taken and the section view is enlarged for all the four states. Figure $2(\mathrm{e})$ is the sectional view taken at any contact point in Figures 2(b), 2(c), and $2(\mathrm{~d})$, which is magnified to describe the contact states. The clearance $c$ is defined as the difference of the two diameters: the diameter of link $3,2 r$, and the slider, $2(r+c)$. The contact process is considered as a continuous compression process and a gradual restitution process. In compression process, a small elastic deformation, namely, penetration $\delta$, occurs at 
the contacting point as shown in the figure. The penetration $\delta$ expression is

$$
\begin{aligned}
& \delta=e-c, \\
& e=\sqrt{\left(O_{2 x}-O_{1 x}\right)^{2}+\left(O_{2 y}-O_{1 y}\right)^{2}},
\end{aligned}
$$

where $O_{1}$ and $O_{2}$ are the center positions of the slider and link 3 , respectively, which can be calculated from the kinematic equations in the generalized coordinates. $e$ is the eccentric distance. The value of $\delta$ is used to detect the motion mode between the two bodies. When $\delta<0$, the mode is free fly; otherwise, $\delta \geq 0$ which means impact or contact occurs; then the contact and the deformation point can be calculated by

$$
\begin{aligned}
T_{1 x} & =O_{1 x}+2(r+c) \cos (\theta), \\
T_{1 y} & =O_{1 y}+2(r+c) \sin (\theta), \\
T_{2 x} & =T_{1 x}+\delta \cos (\theta) \\
T_{2 y} & =T_{1 y}+\delta \sin (\theta) \\
\cos (\theta) & =\frac{O_{2 x}-O_{1 x}}{e}
\end{aligned}
$$

where $T_{1}$ is the initial contacting point on the slider surface. $T_{2}$ is the maximum deformation point.

2.2. Modeling of the Contact Force. The impact-contact duration, in addition to material deformation, is accompanied by energy dissipation. It can be characterized by two items in a normal contact force. At the same time, the tangential relative sliding and viscous phenomenon at contacting point should also be considered through a friction force. As shown in Figure 2(e), when $\delta \geq 0$, the forces $F_{n}$ and $F_{t}$ are applied at the contact point to replace the slide constraint between the two bodies. When $\delta<0$, the force and the slider constraint move away and extra two degrees of freedom are introduced. Under ADAMS, the normal contact force is described by the impact function based on a typical nonlinear spring-damper model, which is composed of two items: the nonlinear pure elastic deformation force expressed by Hertz contact law and the damping force expressed by hysteretic damping item. The normal contact force is given by (3) and can be calculated by the ADAMS function library

$$
F_{N}= \begin{cases}K \delta^{n}+D \dot{\delta} & \delta>0 \\ 0 & \delta \leq 0\end{cases}
$$

where $K$ is the stiffness coefficient, $\delta$ is the relative penetration, $n$ is the exponent set to 1.5 for the mental body, and $D$ is the hysteretic damping coefficient. The parameter $K$ related to the material and geometric properties of the contact bodies can be expressed as

$$
\begin{aligned}
K & =\frac{4}{3} E R^{0.5}, \\
E^{-1} & =\frac{1-v_{1}^{2}}{E_{1}}+\frac{1-v_{2}^{2}}{E_{2}}, \\
\frac{1}{R} & =\frac{1}{R_{1}}+\frac{1}{R_{2}},
\end{aligned}
$$

where $R, v$, and $E$ are the radii, Poisson's ratio, and Young's modulus for contact bodies, respectively.

The damping force is related to relative penetration velocity and damping coefficient $D$, which was widely expressed as a product of a hysteresis damping factor and an exponential item of penetration. The damping factor is defined as a function of the contact stiffness, initial contact velocity, and coefficient of restitution. Over the last decades several formulations for the damping factor have been proposed, which was compared in detail by Alves et al. [38]. In present work, the damping factor is expressed in maximum damping coefficient form and the damping coefficient $D$ is expressed as a step function to avoid discontinuity of damping force:

$$
\begin{aligned}
D & =\operatorname{STEP}\left(\delta, 0,0, d_{\text {max }}, C_{\max }\right) \\
& = \begin{cases}0 & \delta \leq 0 \\
C_{\max }\left(\frac{\delta}{d_{\max }}\right)^{2}\left(3-2 \frac{\delta}{d_{\max }}\right) & 0<\delta<d_{\max } \\
C_{\max } & \delta \geq d_{\text {max }},\end{cases}
\end{aligned}
$$

where $d_{\max }$ is the maximum penetration, which determines when the damping force reaches maximum. $C_{\max }$ is the maximum damping coefficient related to the material, which represents the loss of energy resulting from collisions. When the penetration is less than the maximum, the damping coefficient is a cubic function of the penetration and $C_{\max }$. The damping force increases with the increase in the penetration. When the penetration reaches $d_{\max }$, the damping coefficient raises to the maximum $C_{\max }$ and the damping force reaches maximum. A recommended value for $d_{\max }$ is $0.1 \mathrm{~mm}$ and $C_{\max }$ is one percent of the stiffness coefficient of the material.

The tangential friction force at contact point follows the modified Coulomb's friction law given by

$$
\begin{aligned}
F_{T}= & -\mu F_{N} \frac{v_{T}}{\left|v_{T}\right|}, \\
\mu & = \begin{cases}\mu_{d} & \left|v_{T}\right| \geq v_{d} \\
\operatorname{STEP}\left(\left|v_{T}\right|, v_{d}, \mu_{d}, v_{s}, \mu_{s}\right) & v_{s}<\left|v_{T}\right|<v_{d} \\
\mu_{s} & \left|v_{T}\right| \leq v_{s},\end{cases}
\end{aligned}
$$

where $\mu_{d}$ is the coefficient of dynamic friction. $\mu_{s}$ is the coefficient of static friction. $v_{T}$ is the relative tangential velocity of the contact point. $v_{d}$ and $v_{s}$ are the absolute velocity thresholds for the transition from dynamic friction to static friction. 
TABLE 2: Simulation parameters.

\begin{tabular}{lc}
\hline \multicolumn{2}{c}{ Simulation parameters } \\
\hline$K$ & $1.0 \times 10^{5} \mathrm{~N} / \mathrm{mm}$ \\
$D$ & $58 \mathrm{~N} \cdot \mathrm{s} / \mathrm{mm}$ \\
$\mu_{d}$ & 0.1 \\
$\mu_{s}$ & 0.3 \\
$E$ & $207 \mathrm{GPa}$ \\
$\nu$ & 0.29 \\
Step size & $0.1 \mathrm{~s}$ \\
Simulation time & $120 \mathrm{~s}$ \\
\hline
\end{tabular}

\section{Results and Discussion}

In this section, we study the effect of initial conditions on the dynamic responses of the planar mechanism with two driving links and prismatic pair clearance. Three cases are considered: a series of clearance sizes, a group of constant drive speeds, and a variable drive speed. The simulation model presented in Figure 1 is completed for the three cases and basic conditions listed in Table 2. The numerical solution is performed on ADAMS/Solver. In fact, because of the frequent transition between the different states, the contact instant detection is another important task except the solution of the dynamic equation for numerical issue in impact-contact events. If the contact instant and point are not detected precisely, the penetration and the contact force may become abnormally large and eventually result in the termination of the integration process. For accuracy and efficiency variable time step integral algorithms are widely utilized to gradually narrow the scope of the detection according to the calculation of the distance between the contacting bodies. Other measures like small time step, short simulation time, simple model, and so forth are also effective for finding the contact instant exactly. In the present work, the default stiff integrator, GSTIFF, and the default integrator formulation, I3, were selected for better computational efficiency and good results. The corrector controls the integration tolerance of 0.001 and the simulation is set to 10 periods of link 1 revolution. In order to avoid the contact detection failure due to the influence of the large amount of intermediate data that occurred during the long time simulation, a larger step size was selected to run all simulations continuous.

Implementing the numerical simulation, the performances of velocity and position of the mass center of link 3 are presented to exhibit the dynamic responses of the mechanism at different initial conditions. Furthermore, FFT, phase plane, Poincaré section, and largest Lyapunov exponent are calculated based on the simulation data to predict the system's nonlinear behaviors in three cases. FFT (fast Fourier transform) converts a time domain signal of infinite duration into a continuous spectrum composed of an infinite number of sinusoids. It can be used to analyze the motion of system in the frequency domain. In general, periodic signals give peaks at a fundamental and its harmonics; quasi periodic signals give peaks at linear combinations of two or more irrationally related frequencies; and chaotic dynamics give broad band components to the spectrum [39]. Phase plane describes the relationship between the trajectories evolution and the various state parameters, in which each possible state corresponds to one unique point (attractor). Periodic motion corresponds to closed trajectories and chaos motion corresponds to a group of random separated points of the never closed trajectories (strange attractor) in a certain region [40]. Poincaré sections are mathematical abstractions which are often useful in highlighting the behavior of systems in terms of periodic, quasi-periodic, and chaotic or nonlinear motion. A Poincaré section consists of plotting the value of two components: derivative of the state vector versus the vector itself, that is, $y(t)$ and $y^{\prime}(t)$ [41]. The Lyapunov exponents provide a measure of the sensitivity of the system to its initial conditions. They describe an average rate of divergence or convergence of two neighboring trajectories in phase space, thus providing an indication of the sensitivity of a dynamic system to small local perturbations and distinguishing the chaotic and nonchaotic behaviors of the system $[42,43]$. We use the Lyapunov exponents for quantitative analysis of nonlinear behaviors.

3.1. Influence of the Clearance Size. In this section, the dynamic behaviors of the mechanism with a series of clearance sizes are mainly exhibited and discussed. The clearance series is set as $0.1,0.2,0.3,0.4,0.5$, and $0.75 \mathrm{~mm}$. The input rotation speeds on link 1 and link 2 are $\omega_{1}=30 \mathrm{~d} / \mathrm{s}$ and $\omega_{2}=$ $50 \mathrm{~d} / \mathrm{s}$, respectively. Figure 3 exhibits the velocity responses of link 3 mass center $G$. It is concluded that the velocity of link 3 is influenced by the existence of the clearance. The frequency and the amplitude of fluctuation increase as the clearance size increases. This means the impact-contact is more serious in the larger clearance joint. Figure 4 shows the deviation of the mass center position relative to the ideal position (clearance $=0$ ) which increases with the clearance size. The two figures demonstrate that the impact-contact between the slider and link 3 affects the accuracy of link 3 motion, increases in the clearance, and decreases in the precision of the motion.

Figures 5(a) and 5(b) show the comparison of the FFT of center $G$ displacement data when the clearance is 0 and $0.1 \mathrm{~mm}$, respectively. From Figure 5(b), it can be seen that the Fourier spectrum is a continuous broadband spectrum and has broader peaks as compared to Figure 5(a), which indicates that the motion of the system is not periodic or quasi-periodic. Figure 6 shows the phase plane of the velocity versus displacement of center $G$; the dynamic behavior is period with closed and smooth orbit in the ideal system and tends to be chaotic with the existence of the clearance. Figure 7 shows the Poincaré section, which concludes that one point/orbit on the section is consistent with period behavior of the system without clearance. However, the system with clearance exhibits the chaotic nature with the dense points filling up the section in fractal structure. It can also be concluded that, as the points increase, they get more dispersed with the increase in clearance, which further indicates that the system is more unpredictable. The chaotic 

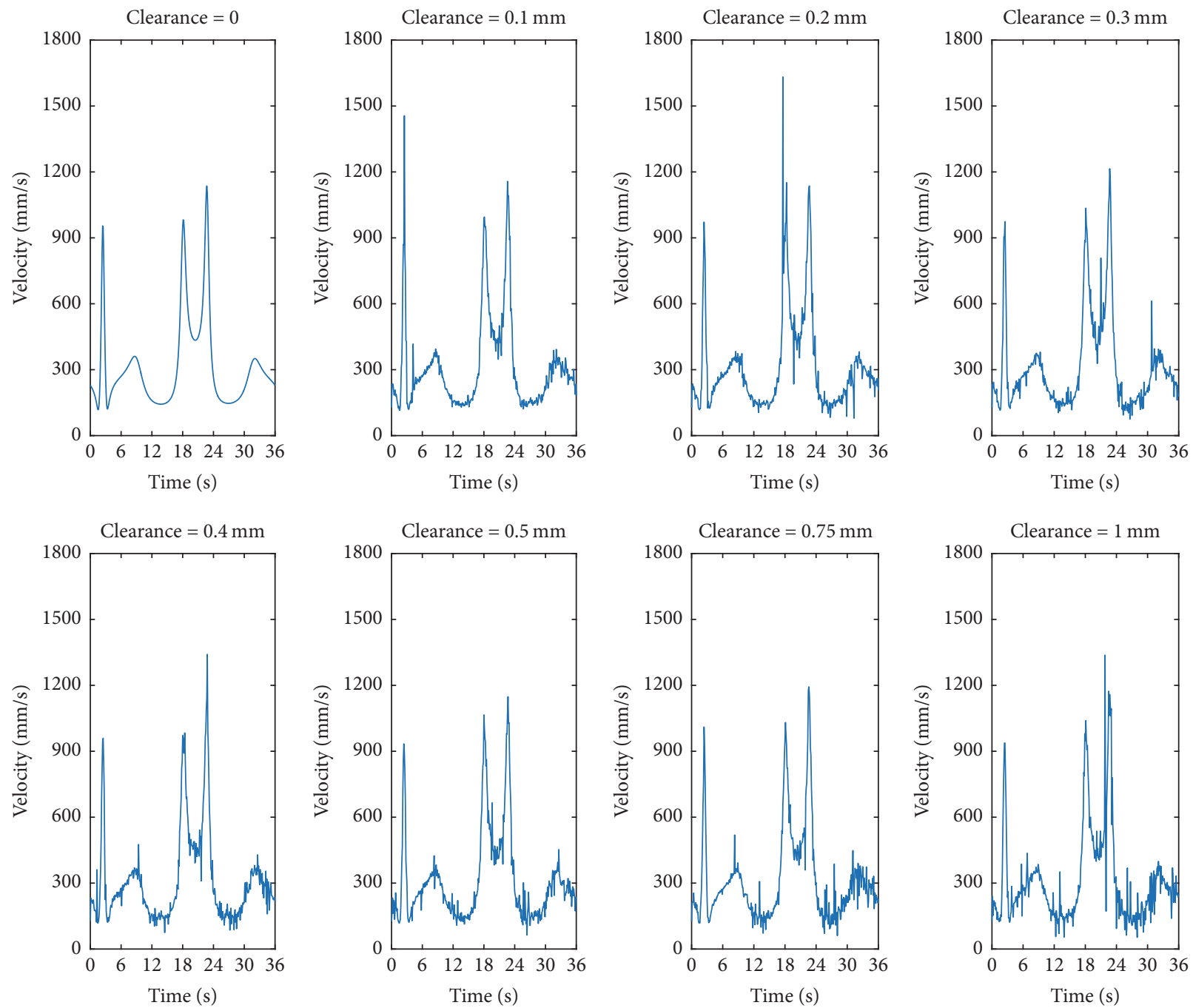

Figure 3: The velocity of mass center $G$ at different clearance sizes.

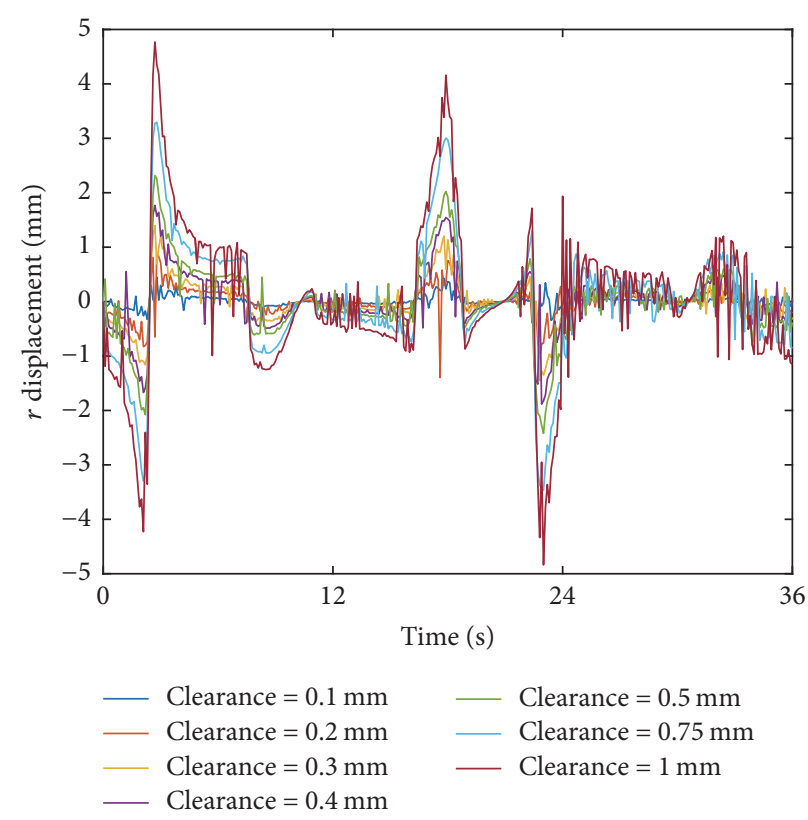

Figure 4: The deviation of the mass center $G$ position relative to the ideal position. 


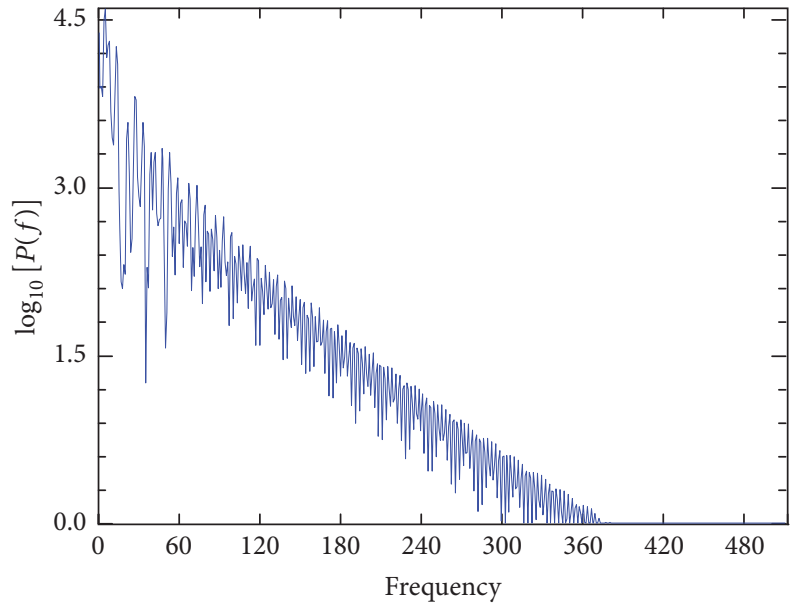

(a) Clearance $=0$

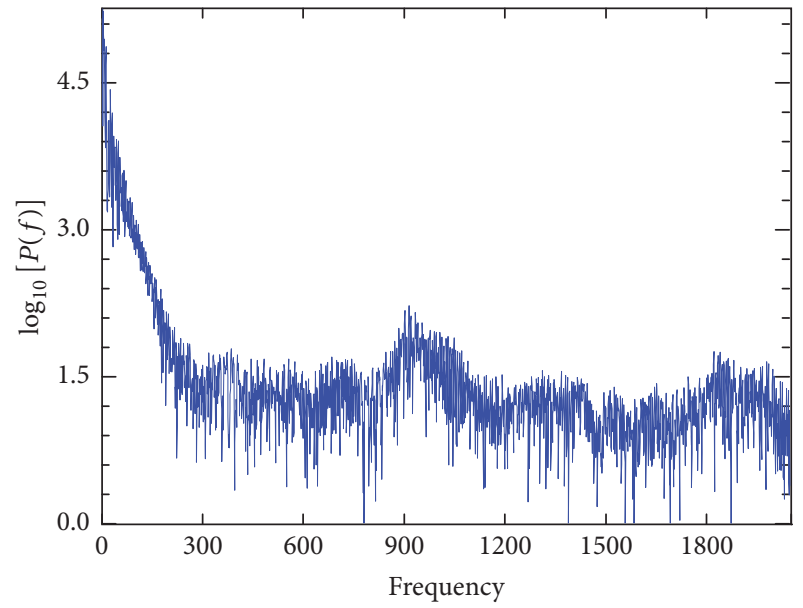

(b) Clearance $=0.1 \mathrm{~mm}$

FIgURE 5: Fourier power spectrum of the data.
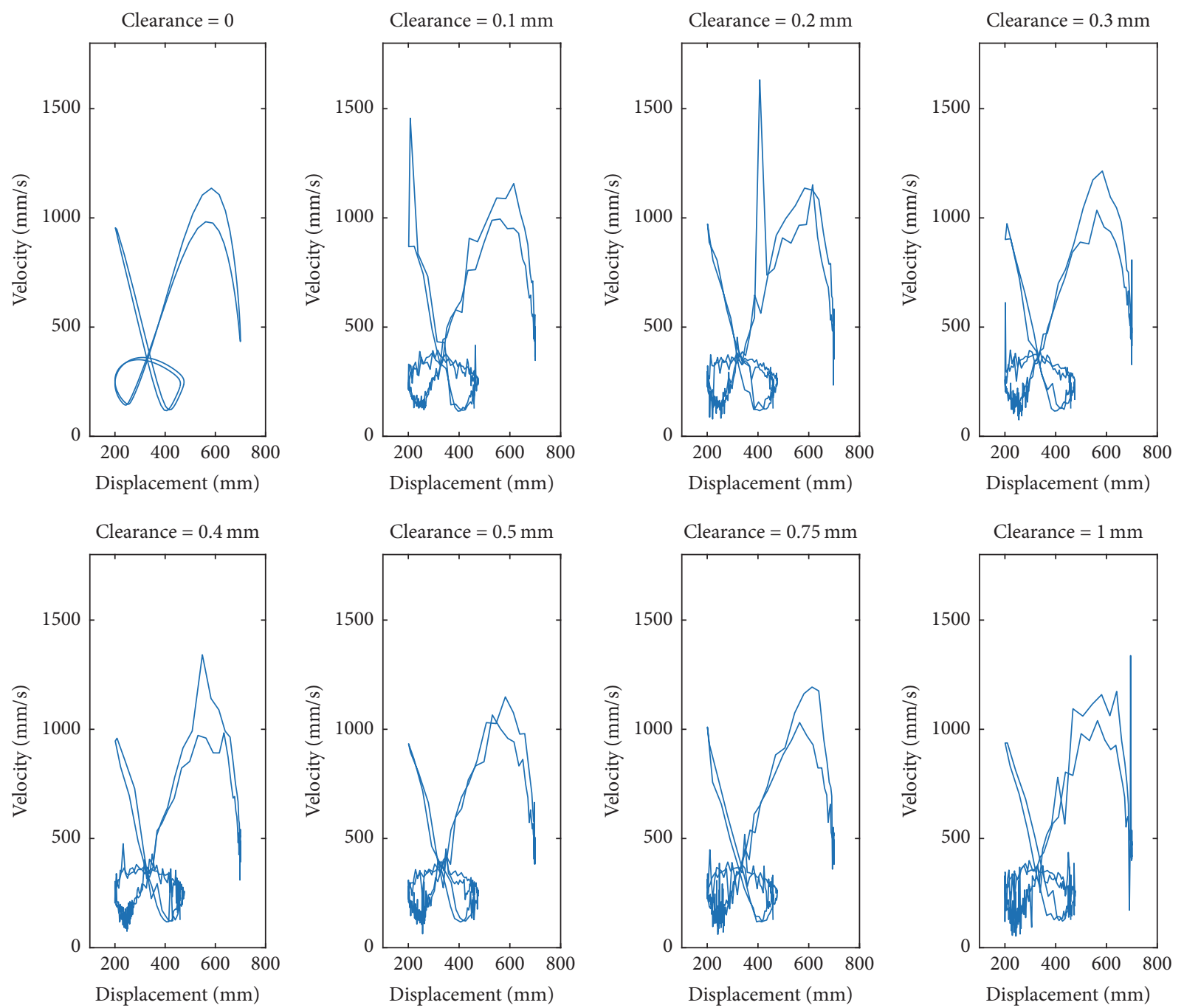

Figure 6: Phase plane. 

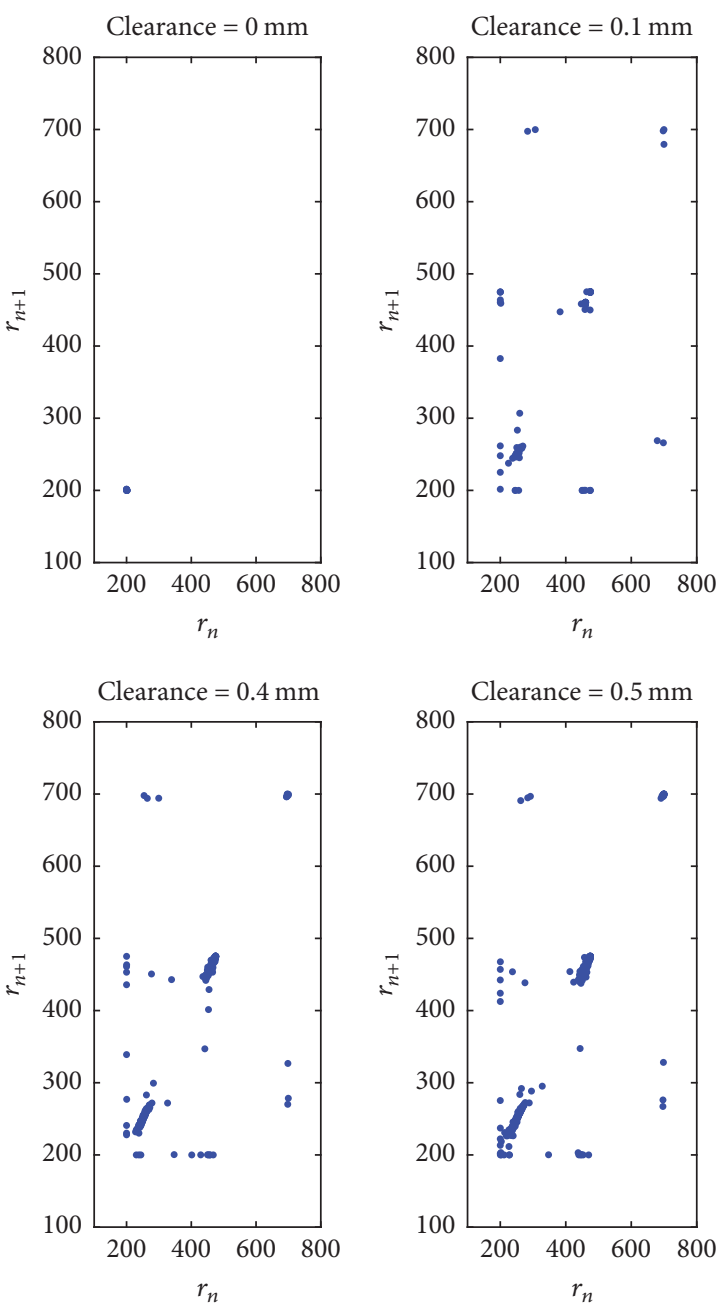
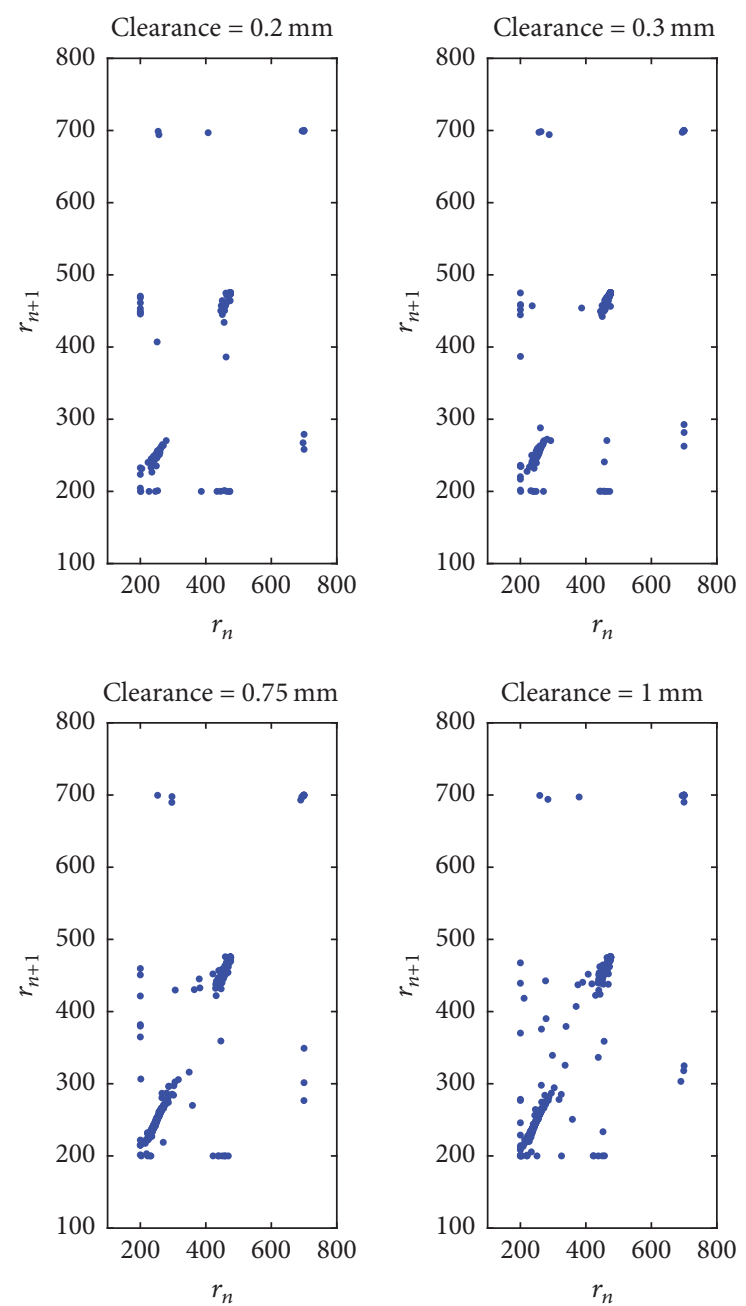

FIgURE 7: Poincaré section.

behavior is related to the unpredictable and random motion states between the two elements of the clearance joints, due to which there is uncertainty in the contact and the friction force. Furthermore the system is extremely sensitive to initial conditions of the clearance size. Figure 8 shows the largest Lyapunov exponents with respect to the series clearance size. In this work, a practical algorithm provided by Rosenstein et al. [44] is adapted to calculate the largest Lyapunov exponent. Based on the simulation results of $G$ position in the form of time series, the state space is reconstructed using the method of time delays; thus the Euclidean distance between the nearest neighbors is deduced. Then the largest Lyapunov exponent is calculated through the slope of the linear bestfit of the Euclidean distance. A negative Lyapunov exponent indicates local stability, whereas a positive Lyapunov exponent indicates local instability. Larger Lyapunov exponents indicate greater sensitivity to local perturbations [43]. From Figure 8, two points can be concluded: the system with clearance has divergence trend and chaotic nature signified by the largest Lyapunov exponents which are all bigger than zero; the largest Lyapunov exponents increase with the increase in clearance size.
TABLE 3: Groups of link 1 speeds.

\begin{tabular}{lccccc}
\hline Groups & 1 & 2 & 3 & 4 & 5 \\
\hline$\omega_{1}(\mathrm{~d} / \mathrm{s})$ & 30 & 40 & 50 & 60 & 70 \\
$\omega_{2}(\mathrm{~d} / \mathrm{s})$ & 50 & 50 & 50 & 50 & 50 \\
\hline
\end{tabular}

3.2. Influence of the Constant Input Speed. Influence of the input rotation speeds on the dynamic behavior of the planar mechanism with clearance joint is investigated in this section. Four groups of constant input speeds are set, respectively, in Table 3; the clearance size is set to $0.5 \mathrm{~mm}$. Figure 9 shows the largest Lyapunov exponents calculated for the four groups of input speeds. It is clear that the system having clearance exhibits nonlinear behavior at different link 1 speeds. It can also be seen that the largest Lyapunov exponents increase as link 1 speeds increase. Also, the velocity and position response shows the decrease in precision with the increase in input speeds.

3.3. Influence of the Variable Input Speed. In this section, the clearance size is set to the same series as Section 3.1. The 


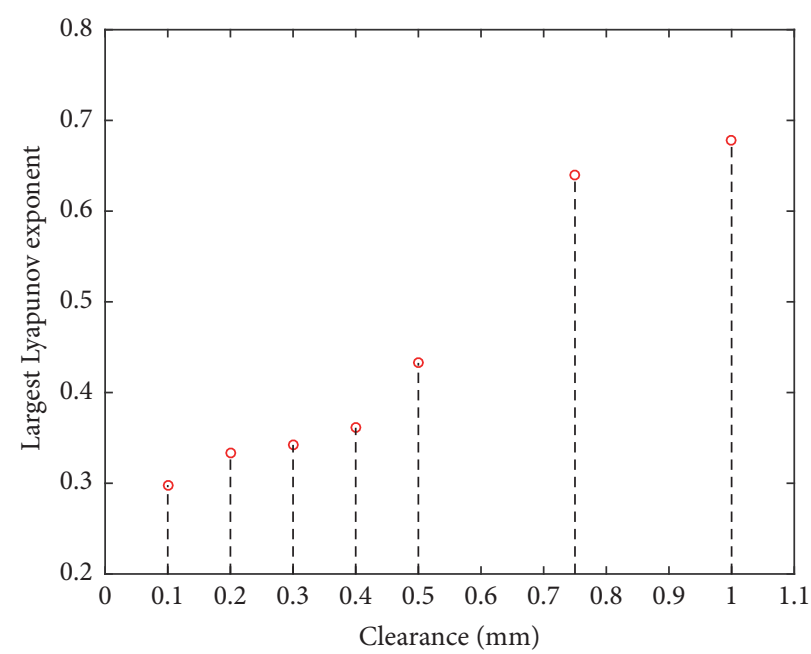

FIGURE 8: Largest Lyapunov exponents for a set of series clearance size.

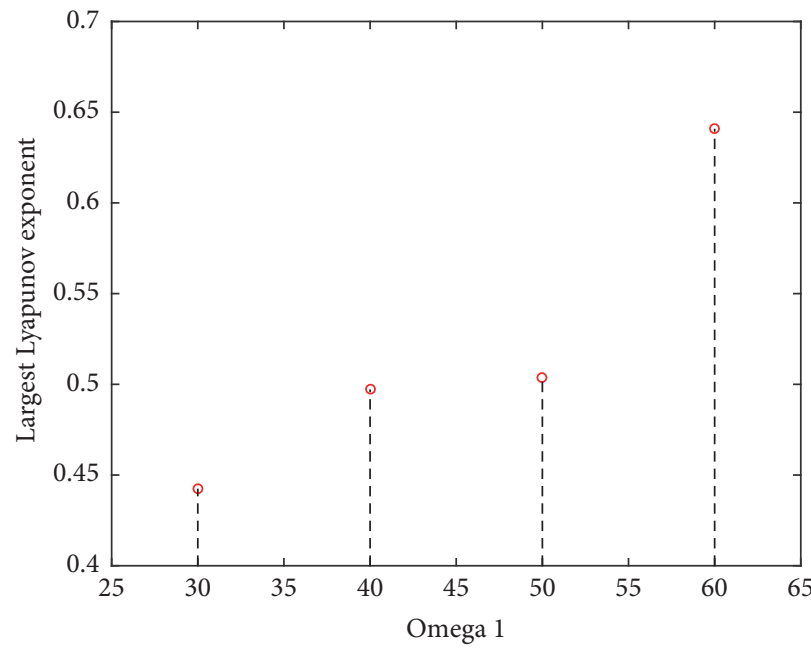

FIGURE 9: Largest Lyapunov exponent for different link 1 speeds and clearance $0.5 \mathrm{~mm}$.

input speed is described by a profile calculated through the following formulation:

$$
\begin{aligned}
& M_{1}=M_{10}\left(1-\frac{\omega_{1}}{\omega_{10}}\right), \\
& M_{2}=M_{10}\left(1-\frac{\omega_{2}}{\omega_{20}}\right),
\end{aligned}
$$

where $M_{1}$ and $M_{2}$ are the torques with constant rotation speeds $\omega_{10}$ of $30 \mathrm{~d} / \mathrm{s}$ and $\omega_{20}$ of $50 \mathrm{~d} / \mathrm{s}$, respectively, in the mechanism with idea joint. $M_{10}$ is a constant value.

From (7), two variable input speeds $\omega_{1}$ on link 1 and $\omega_{2}$ on link 2 can be calculated and plotted versus time as shown in Figure 10.

The largest Lyapunov exponents calculated at the condition of variable input speeds and a series clearance size are shown in Figure 11. The system exhibits the same nonlinear tendency as in the other two cases.

\section{Conclusion}

In this paper, the effect of clearance size and input speed on the dynamic performance is investigated on a mechanism with two driving links. The continuous contact force inserted in the multibody dynamic methodology is employed to build the numerical model of system. The simulation results show that the dynamic of the mechanism system is changed dramatically. This change can be seen from the increase fluctuations of motion as the clearance size and input speed increase. The nonlinear characteristic of the mechanism system is analyzed using FFT, phase plane, Poincaré section, and largest Lyapunov exponents. The system has the tendency to move from chaotic to period with decrease in clearance. 

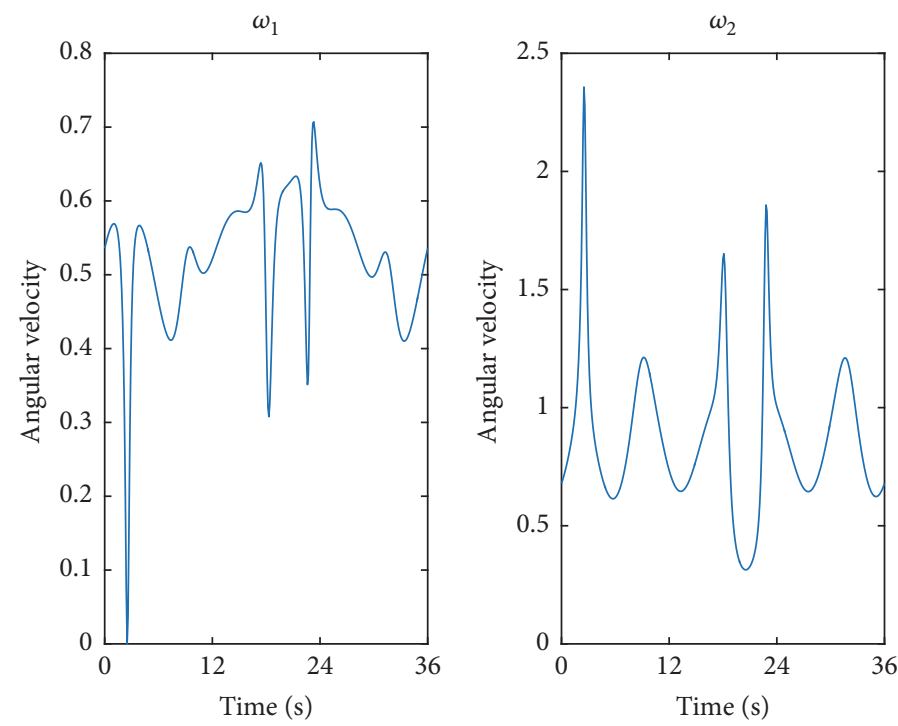

FIgURE 10: The variable angular velocity $\omega_{1}$ on link 1 and $\omega_{2}$ on link 2 .

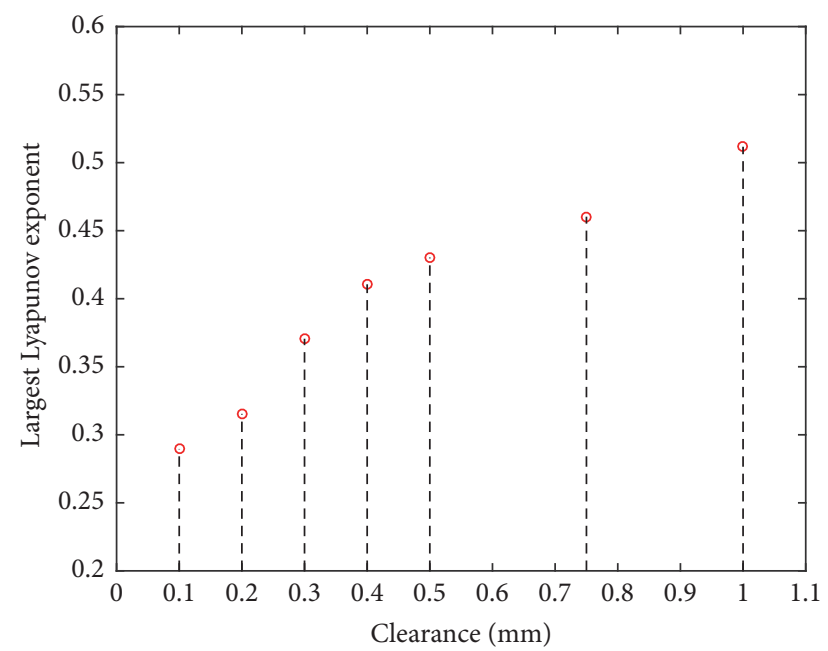

FIGURE 11: Largest Lyapunov exponents for variable input speeds and a series clearance size.

The largest Lyapunov exponents increase with the increase in clearance whether the input speed is constant or variable. Change in input speed gives similar results when the clearance set to constant, that is, increase in input speed, will increase the largest Lyapunov exponents.

\section{Conflicts of Interest}

The authors declare that there are no conflicts of interest regarding the publication of this paper.

\section{Acknowledgments}

This work was partially supported by the Shanghai Key Laboratory for Networked Manufacturing and Enterprise Information.

\section{References}

[1] S. Dubowsky and F. Freudenstein, "Dynamic analysis of mechanical systems with clearances part 2: dynamic response," Journal of Engineering for Industry, vol. 93, no. 1, pp. 310-316, 1971.

[2] S. Erkaya and I. Uzmay, "Experimental investigation of joint clearance effects on the dynamics of a slider-crank mechanism," Multibody System Dynamics, vol. 24, no. 1, pp. 81-102, 2010.

[3] P. Flores, C. S. Koshy, H. M. Lankarani, J. Ambrósio, and J. C. P. Claro, "Numerical and experimental investigation on multibody systems with revolute clearance joints," Nonlinear Dynamics, vol. 65, no. 4, pp. 383-398, 2011.

[4] M. Houfek and L. Houfek, "Bifurcation and chaos in couplings with clearance," Advanced Materials Research, vol. 936, pp. 2120-2124, 2014.

[5] S. Yaqubi, M. Dardel, and H. M. Daniali, "Nonlinear dynamics and control of crank-slider mechanism with link flexibility and joint clearance," Proceedings of the Institution of Mechanical Engineers, Part C: Journal of Mechanical Engineering Science, vol. 230, no. 5, pp. 737-755, 2016.

[6] Z. Wang, Q. Tian, H. Hu, and P. Flores, "Nonlinear dynamics and chaotic control of a flexible multibody system with uncertain joint clearance," Nonlinear Dynamics, vol. 86, no. 3, pp. 1571-1597, 2016.

[7] M. Dupac and D. G. Beale, "Dynamic analysis of a flexible linkage mechanism with cracks and clearance," Mechanism and Machine Theory, vol. 45, no. 12, pp. 1909-1923, 2010.

[8] P. Flores, J. Ambrósio, J. C. P. Claro, and H. M. Lankarani, "Dynamic behaviour of planar rigid multi-body systems including revolute joints with clearance," Proceedings of the Institution of Mechanical Engineers, Part K: Journal of Multi-body Dynamics, vol. 221, no. 2, pp. 161-174, 2007.

[9] A. B. Nordmark, "Non-periodic motion caused by grazing incidence in an impact oscillator," Journal of Sound and Vibration, vol. 145, no. 2, pp. 279-297, 1991.

[10] M. Zukovic and L. Cveticanin, "Chaotic responses in a stable duffing system of non-ideal type," JVC/Journal of Vibration and Control, vol. 13, no. 6, pp. 751-767, 2007. 
[11] S. Erkaya and I. Uzmay, "Investigation on effect of joint clearance on dynamics of four-bar mechanism," Nonlinear Dynamics, vol. 58, no. 1-2, pp. 179-198, 2009.

[12] O. Muvengei, J. Kihiu, and B. Ikua, "Dynamic analysis of planar multi-body systems with LuGre friction at differently located revolute clearance joints," Multibody System Dynamics, vol. 28, no. 4, pp. 369-393, 2012.

[13] S. P. Timoshenko and J. M. Gere, Theory of Elastic Stability, Courier Corporation, 2009.

[14] H. Hertz, "Üher die berührung fester elastischer körper (on the contact of elastic solids)," Journal fur die Reine und Andegwandte Mathematik, vol. 92, pp. 156-171, 1882.

[15] K. Hunt and F. Crossley, "Coefficient of restitution interpreted as damping in vibroimpact," Journal of Applied Mechanics, vol. 42, no. 2, pp. 440-445, 1975.

[16] H. Lankarani and P. E. Nikravesh, "A contact force model with hysteresis damping for impact analysis of multibody systems," Journal of Mechanical Design, vol. 112, no. 3, pp. 369-376, 1990.

[17] P. Ravn, "A continuous analysis method for planar multibody systems with joint clearance," Multibody System Dynamics, vol. 2, no. 1, pp. 1-24, 1998.

[18] P. Flores and J. Ambrósio, "Revolute joints with clearance in multibody systems," Computers \& Structures, vol. 82, no. 17, pp. 1359-1369, 2004.

[19] A. L. Schwab, J. P. Meijaard, and P. Meijers, "A comparison of revolute joint clearance models in the dynamic analysis of rigid and elastic mechanical systems," Mechanism and Machine Theory, vol. 37, no. 9, pp. 895-913, 2002.

[20] Z. F. Bai and Y. Zhao, "Dynamic behaviour analysis of planar mechanical systems with clearance in revolute joints using a new hybrid contact force model," International Journal of Mechanical Sciences, vol. 54, no. 1, pp. 190-205, 2012.

[21] P. Flores, M. MacHado, M. T. Silva, and J. M. Martins, "On the continuous contact force models for soft materials in multibody dynamics," Multibody System Dynamics, vol. 25, no. 3, pp. 357375, 2011.

[22] M. Gharib and Y. Hurmuzlu, "A new contact force model for low coefficient of restitution impact," Journal of Applied Mechanics, Transactions ASME, vol. 79, no. 6, Article ID 064506, 2012.

[23] J. Ma, L. Qian, G. Chen, and M. Li, "Dynamic analysis of mechanical systems with planar revolute joints with clearance," Mechanism and Machine Theory, vol. 94, article no. 2549, pp. 148-164, 2015.

[24] T. Kane, "Impulsive motions," Journal of Applied Mechanics, vol. 29, no. 4, pp. 715-718, 1962.

[25] D. B. Marghitu and Y. Hurmuzlu, "Nonlinear dynamics of an elastic rod with frictional impact," Nonlinear Dynamics. An International Journal of Nonlinear Dynamics and Chaos in Engineering Systems, vol. 10, no. 2, pp. 187-201, 1996.

[26] E. D. Stoenescu and D. B. Marghitu, "Dynamic analysis of a planar rigid-link mechanism with rotating slider joint and clearance," Journal of Sound and Vibration, vol. 266, no. 2, pp. 394-404, 2003.

[27] I. Khemili and L. Romdhane, "Dynamic analysis of a flexible slider-crank mechanism with clearance," European Journal of Mechanics-A/Solids, vol. 27, no. 5, pp. 882-898, 2008.

[28] G. B. Daniel and K. L. Cavalca, "Analysis of the dynamics of a slider-crank mechanism with hydrodynamic lubrication in the connecting rod-slider joint clearance," Mechanism and Machine Theory, vol. 46, no. 10, pp. 1434-1452, 2011.
[29] E. Zheng, R. Zhu, S. Zhu, and X. Lu, "A study on dynamics of flexible multi-link mechanism including joints with clearance and lubrication for ultra-precision presses," Nonlinear Dynamics. An International Journal of Nonlinear Dynamics and Chaos in Engineering Systems, vol. 83, no. 1-2, pp. 137-159, 2016.

[30] P. Gu, S. Dubowsky, and C. Mavroidis, "The design implications of chaotic and near-chaotic vibrations in machines," in Proceedings of the 1998 ASME Design Technical Conferences, 1998.

[31] K. Kappaganthu and C. Nataraj, "Nonlinear modeling and analysis of a rolling element bearing with a clearance," Communications in Nonlinear Science and Numerical Simulation, vol. 16, no. 10, pp. 4134-4145, 2011.

[32] L. D. Seneviratne and S. W. E. Earles, "Chaotic behaviour exhibited during contact loss in a clearance joint of a four-bar mechanism," Mechanism and Machine Theory, vol. 27, no. 3, pp. 307-321, 1992.

[33] F. Farahanchi and S. W. Shaw, "Chaotic and periodic dynamics of a slider-crank mechanism with slider clearance," Journal of Sound and Vibration, vol. 177, no. 3, pp. 307-324, 1994.

[34] P. Flores, "A parametric study on the dynamic response of planar multibody systems with multiple clearance joints," Nonlinear Dynamics, vol. 61, no. 4, pp. 633-653, 2010.

[35] A. Azimi Olyaei and M. R. Ghazavi, "Stabilizing slider-crank mechanism with clearance joints," Mechanism and Machine Theory, vol. 53, pp. 17-29, 2012.

[36] O. Muvengei, J. Kihiu, and B. Ikua, "Numerical study of parametric effects on the dynamic response of planar multi-body systems with differently located frictionless revolute clearance joints," Mechanism and Machine Theory, vol. 53, pp. 30-49, 2012.

[37] Y. Tang, Z. Chang, X. Dong, Y. Hu, and Z. Yu, "Nonlinear dynamics and analysis of a four-bar linkage with clearance," Frontiers of Mechanical Engineering, vol. 8, no. 2, pp. 160-168, 2013.

[38] J. Alves, N. Peixinho, M. T. Da Silva, P. Flores, and H. M. Lankarani, "A comparative study of the viscoelastic constitutive models for frictionless contact interfaces in solids," Mechanism and Machine Theory, vol. 85, pp. 172-188, 2015.

[39] P. Welch, "The use of fast fourier transform for the estimation of power spectra: a method based on time averaging over short, modified periodograms," IEEE Transactions on Audio and Electroacoustics, vol. 15, no. 2, pp. 70-73, 1967.

[40] M. W. Hirsch, S. Smale, and R. L. Devaney, Differential Equations, Dynamical Systems, and an Introduction to Chaos, Academic press, 2012.

[41] S. Wiggins, Introduction to Applied Nonlinear Dynamical Systems and Chaos, vol. 2, Springer Science+Business Media, 2003.

[42] A. Wolf, J. B. Swift, H. L. Swinney, and J. A. Vastano, "Determining Lyapunov exponents from a time series," Physica D. Nonlinear Phenomena, vol. 16, no. 3, pp. 285-317, 1985.

[43] J. B. Dingwell and L. C. Marin, "Kinematic variability and local dynamic stability of upper body motions when walking at different speeds," Journal of Biomechanics, vol. 39, no. 3, pp. 444-452, 2006.

[44] M. T. Rosenstein, J. J. Collins, and C. J. De Luca, "A practical method for calculating largest Lyapunov exponents from small data sets," Physica D. Nonlinear Phenomena, vol. 65, no. 1-2, pp. 117-134, 1993. 


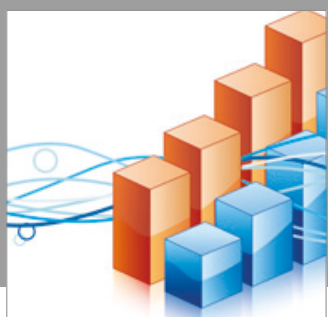

Advances in

Operations Research

vatersals

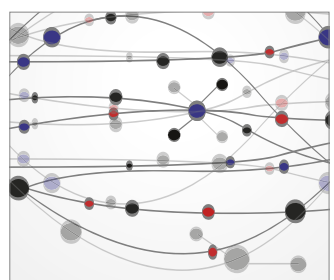

\section{The Scientific} World Journal
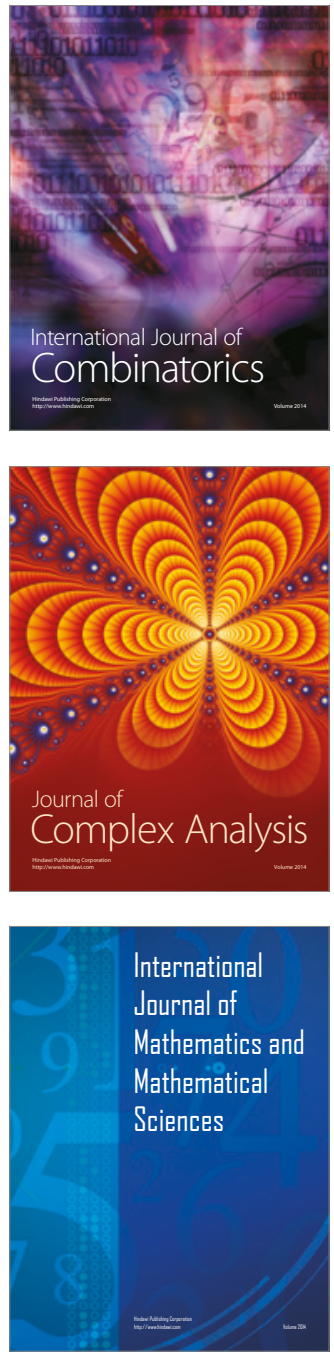
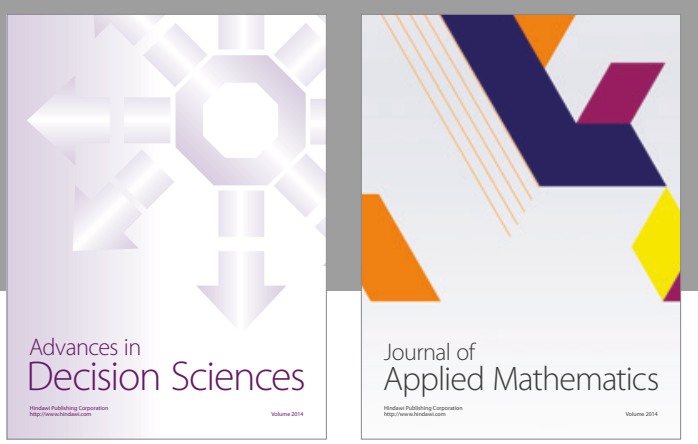

Algebra

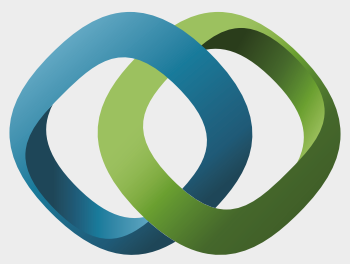

\section{Hindawi}

Submit your manuscripts at

https://www.hindawi.com
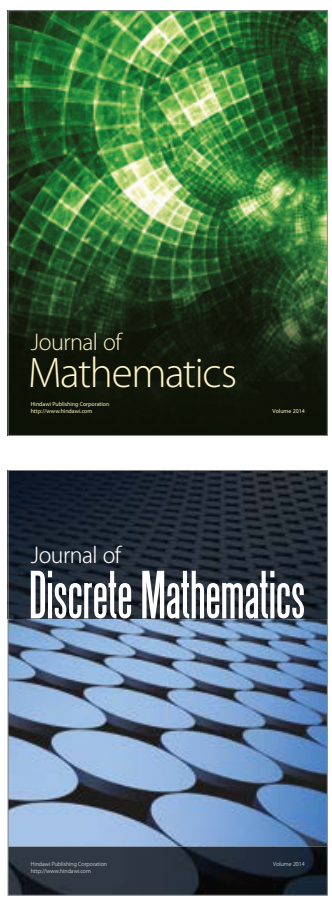

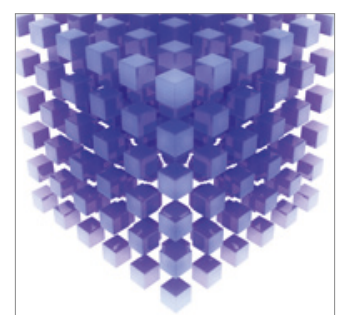

Mathematical Problems in Engineering
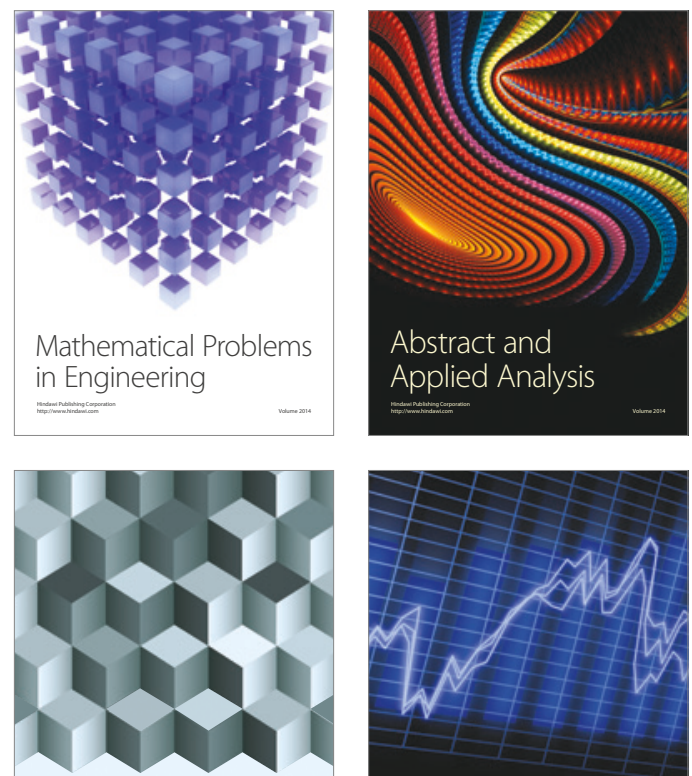

Journal of

Function Spaces

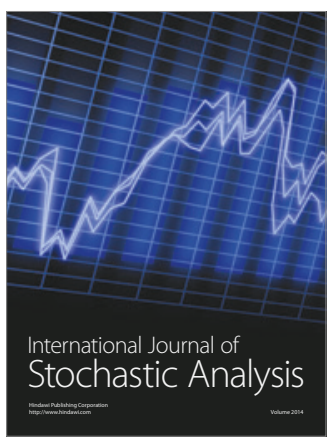

Probability and Statistics
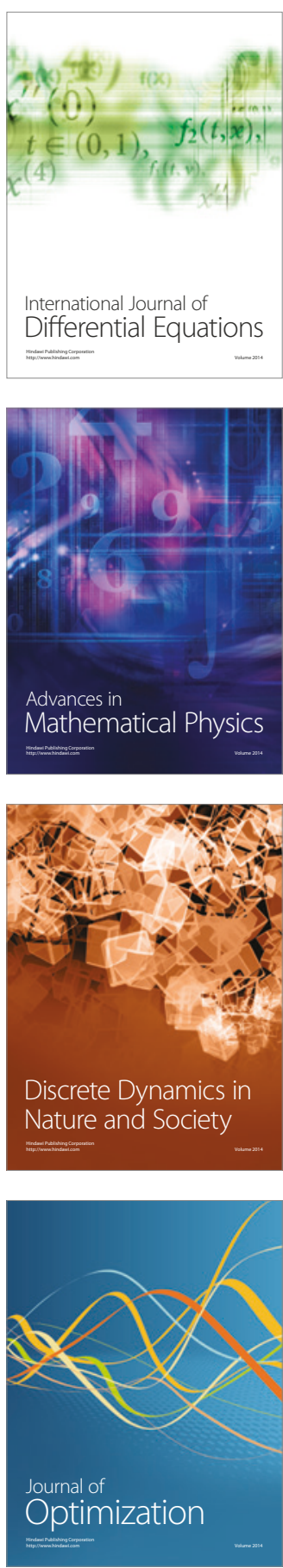